\title{
Investigation of 316L Stainless Steel by Flame Hardening Process
}

\author{
Dr. Ram. Subbiah ${ }^{1}$, G. Pooja ${ }^{2}$, S. Pallavi ${ }^{3}$, T. Likitha ${ }^{4}$, Dr. R. Rajavel ${ }^{5}$ \\ ${ }^{1}$ Associate Professor, Mechanical Engineering Department, GRIET, Hyderabad, India \\ ${ }^{2,3,4}$ B.Tech Mechanical Engineering Department, GRIET, Hyderabad, India \\ ${ }^{5}$ Professor \& HOD, Mechanical Engineering Department, AMET University, Chennai, India
}

\begin{abstract}
Austenitic stainless steel offer great imperviousness to general erosion because of the development of a detached surface film. They are broadly utilized as a part of the sustenance and concoction preparing ventures and in addition in biomaterial applications. In any case, they can experience the ill effects of setting erosion in chloride particle containing arrangements. All things considered, in the meantime they have discovered little use in mechanical building applications in view of their low hardness and poor wear resistance. In this examination work, to enhance the previously mentioned reasons, surface solidifying by Flame hardening procedure is done. It has for some time been an outstanding a warm treatment for enhancing the surface properties of austenitic stainless steel. The examples were fire solidified for 5 minutes, 10 minutes and 15 minutes separately. Wear test for every one of the examples were completed by stick on plate testing process. The outcomes were contrasted and an untreated specimen and finished up with metallographic tests like optical tiny tests and examining electron magnifying lens tests.
\end{abstract}

Keywords - Austenitic Stainless Steel, Poor Wear Resistance Flame Hardening.

\section{INTRODUCTION}

Low temperature flame hardening can create another stage with high hardness and great consumption resistance on austenitic stainless steel surfaces. It does as such by the development of a non balance super immersed layer, what is called S-stage or extended austenite stage. The surface layer as being hard and erosion resistance with anticorrosion properties are proportional to the first material. Numerous specialists have created such altered layer on austenitic stainless steels by different warmth treatment forms at low temperatures $\left(<450^{\circ} \mathrm{c}\right)$. It is by and large suspected that high temperature treatment may bring about to build more fragility with more hardness, which may prompt disappointment of material. Precipitation of lower carbon content in the stainless material will enhance slight hardness.

\section{EXPERIMENTAL WORK}

AISI 316L Stainless steel were subjected to flame hardening processes. Three samples were prepared by mechanical cutting of bulk material to disc of diameter 100 $\mathrm{mm}$ and $10 \mathrm{~mm}$ thickness with \pm 0.05 mmdimensional accuracy. The samples were mechanically polished using $\mathrm{SiC}$ abrasive paper from coarse to fine grade following standard polishing procedures. The samples were finally cleaned ultrasonically. Three samples were subjected to flame hardening process where oxy acetylene gases are diffused into stainless steel specimen.

\section{WEAR TEST}

Pin on disc apparatus were used to conduct the wear test. The samples undergone with heat treatment are undergone under pin on disc testing apparatus. Stainless steel Disc of diameter $100 \mathrm{~mm}$ and thickness of $10 \mathrm{~mm}$ were subjected to flame hardening process. The pin specimens were replaced one by one against the disc specimen. The disc is rotated to a constant speed of $1000 \mathrm{rpm}$ and the pins were replaced with one by one with a time gap of 2 minutes.

\section{METALLOGRAPHIC TESTS}

\subsection{Optical Microscope Results}

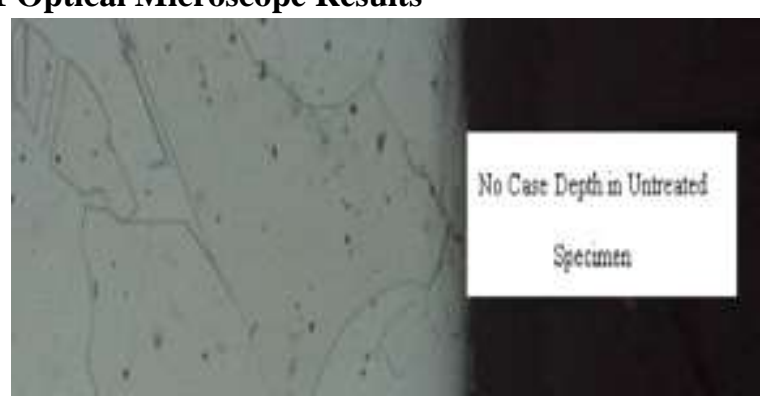

Fig 4.1: Untreated Sample - No Case Depth 


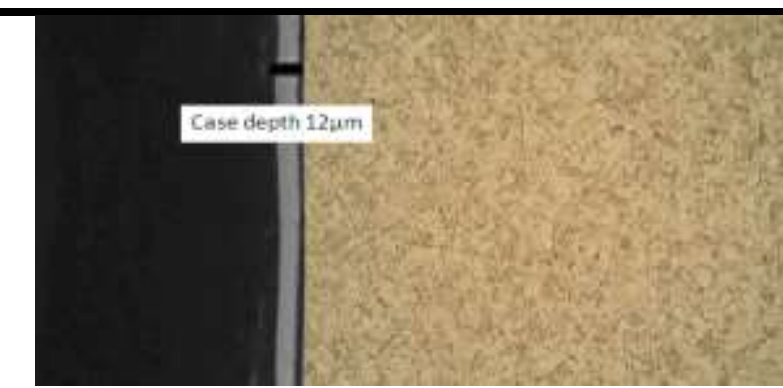

Fig.4.2: Flame hardening - 5 minutes $12 \mu \mathrm{m}$

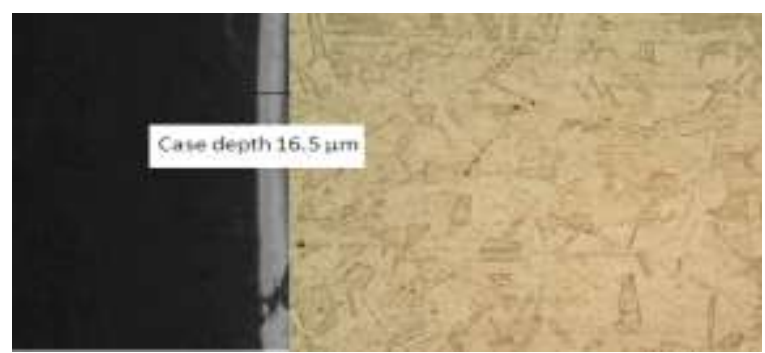

Fig.4.3: Flame hardening - 10 minutes $16.5 \mu \mathrm{m}$

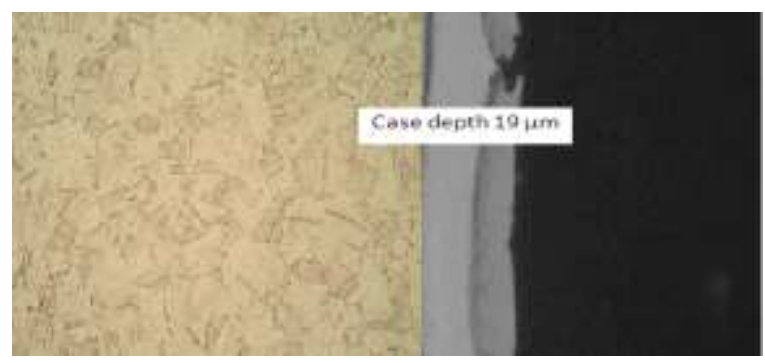

Fig.4.4: Flame hardening - 15 minutes $19 \mu \mathrm{m}$

From the above diagram, it is clearly seen that, untreated stainless steel sample doesn't have any case hardness value, while the flame hardened specimens were found to be 12 $\mu \mathrm{m}, 16.5 \mu \mathrm{m}$ and $19 \mu \mathrm{m}$ respectively. The hardness of the material were determined. The hardness for an untreated sample was found to be $330 \mathrm{Hv}$. While the hardness for the heat treated specimens were found to be $560 \mathrm{HV}_{\mathrm{v}}, 589 \mathrm{Hv}$, $603 \mathrm{Hv}$

\subsection{Scanning Electron Microscope Results:}

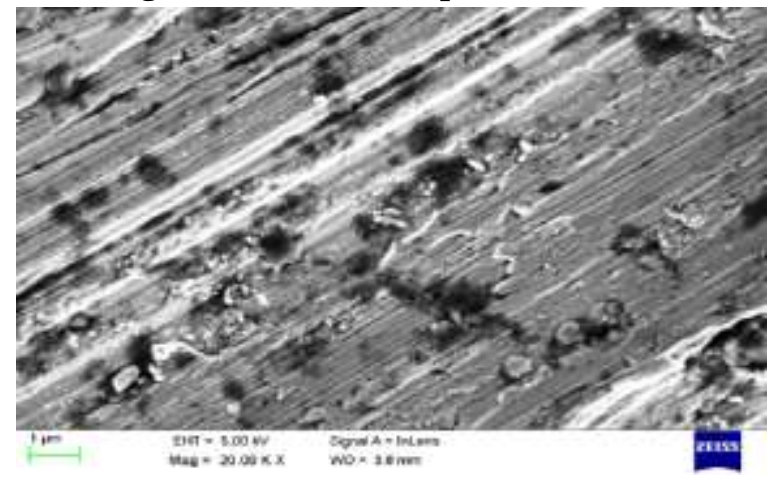

Fig.5: Untreated specimen SEM image

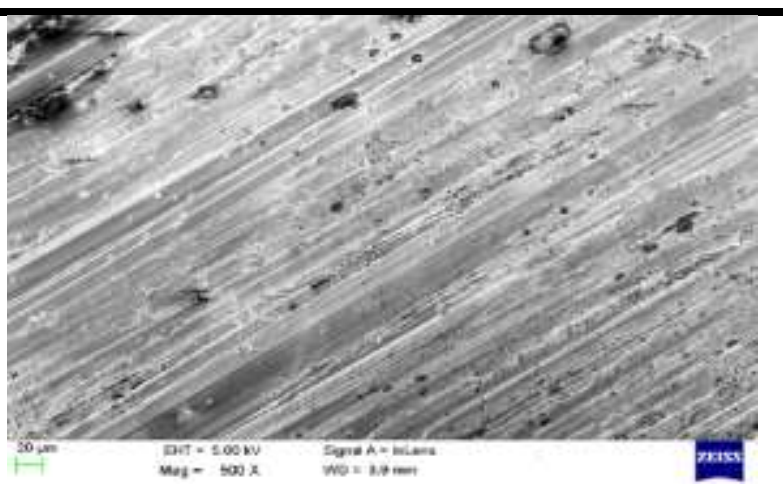

Fig.4.6: Flame hardening - 5 min SEM image

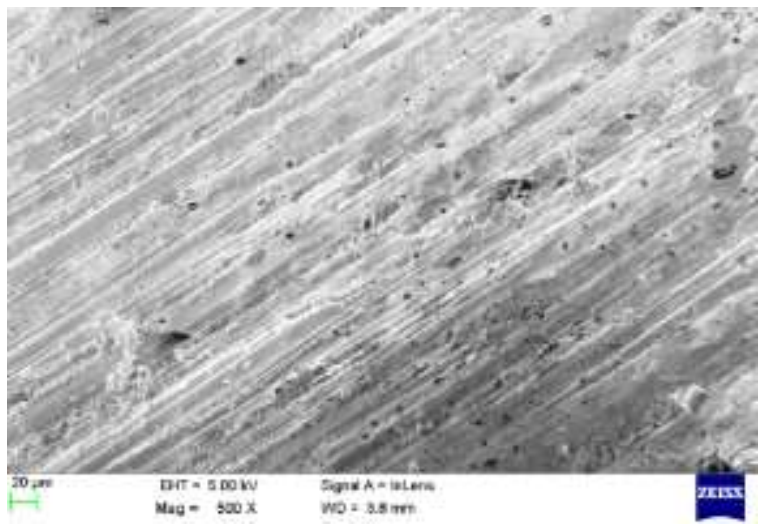

Fig.4.7: Flame hardening - 10 min SEM image

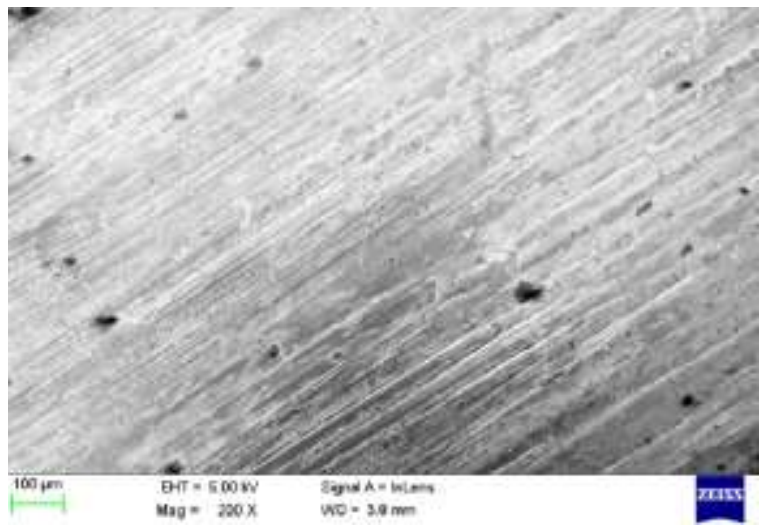

Fig.4.8: Flame hardening - 15 min SEM image

From the wear test results, it is noted that more wear has occurred in untreated sample, where as peel of material gradually decreases as the time of heat treatment process increases. There by wear resistance and hardness are improved, ductility on stainless steel material is enhanced.

\section{CONCLUSION}

From the research work, flame hardenings on stainless steel were being carried out at various timing parameters. Flame hardening improves the hardness of stainless steel material, improve wear resistance. So that ductility is promoted in 
stainless steel material. So that stainless steel material can be used for higher applications like power plant turbine blades, automobile components, marine applications were components are subjected to salt water.

\section{REFERENCES}

[1] M.K. Lee, G.H. Kim, K.H. Kim, W.W. Kim, "Effects of the surface temperature and cooling rate on the residual stresses in a flame hardening of $12 \mathrm{Cr}$ steel" Journal of Materials Processing Technology, Volume 176, Issues 1-3, 6 June 2006, Pages 140-145

[2] M.K. Lee, G.H. Kim, K.H. Kim, W.W. Kim, “Control of surface hardnesses, hardening depths, and residual stresses of low carbon $12 \mathrm{Cr}$ steel by flame hardening" Surface and Coatings Technology, Volume 184, Issues 2-3, 22 June 2004, Pages 239-246

[3] Y.Kevin Chou, "Surface hardening of AISI 4340 steel by machining: a preliminary investigation" Journal of Materials Processing Technology, Volume 124, Issues 1-2, 10 June 2002, Pages 171-177

[4] N.Y. Sari, M. Yilmaz, "Investigation of abrasive + erosive wear behaviour of surface hardening methods applied to AISI 1050 steel" Materials \& Design, Volume 27, Issue 6, 2006, Pages 470-478

[5] Adam Bokota, Sławomir Iskierka," Numerical analysis of phase transformations and residual stresses in steel cone-shaped elements hardened by induction and flame methods, International Journal of Mechanical Sciences, Volume 40, Issue 6, June 1998, Pages 617-629

[6] Abdelatif Belamri, Abdelaziz Ati, Muriel Braccini, Said Azem, "Hypereutectoid steel coatings obtained by thermal flame spraying - Effect of annealing on microstructure, tribological properties and adhesion energy" Surface and Coatings Technology, Volume 263, 15 February 2015, Pages 86-99

[7] Ching An Huang, Ui Wei Lieu, Chin Huo Chuang, "Role of nickel undercoat and reduction-flame heating on the mechanical properties of $\mathrm{Cr}-\mathrm{C}$ deposit electroplated from a trivalent chromium based bath" Surface and Coatings Technology, Volume 203, Issue 19, 25 June 2009, Pages 2921-2926.
[8] Nizamettin Kahraman, Behçet Gülenç, "Abrasive wear behaviour of powder flame sprayed coatings on steel substrates" Materials \& Design, Volume 23, Issue 8, December 2002, Pages 721-725

[9] Chao Zhang, Ga Zhang, Vincent JI, Hanlin Liao, Sophie Costil, Christian Coddet, "Microstructure and mechanical properties of flame-sprayed PEEK coating remelted by laser process" Progress in Organic Coatings, Volume 66, Issue 3, November 2009, Pages 248-253

[10] J. Rauch, G. Bolelli, A. Killinger, R. Gadow, V. Cannillo, L. Lusvarghi, "Advances in High Velocity Suspension Flame Spraying (HVSFS)" Surface and Coatings Technology, Volume 203, Issue 15, 25 May 2009, Pages 2131-2138 